\title{
Product Cycle, Contractibility and Global Sourcing
}

\author{
Xiaoping Chen, \\ Yi Lu, \\ Lianming Zhu
}

\author{
March 2016 \\ EGC Report No: 2016/04
}

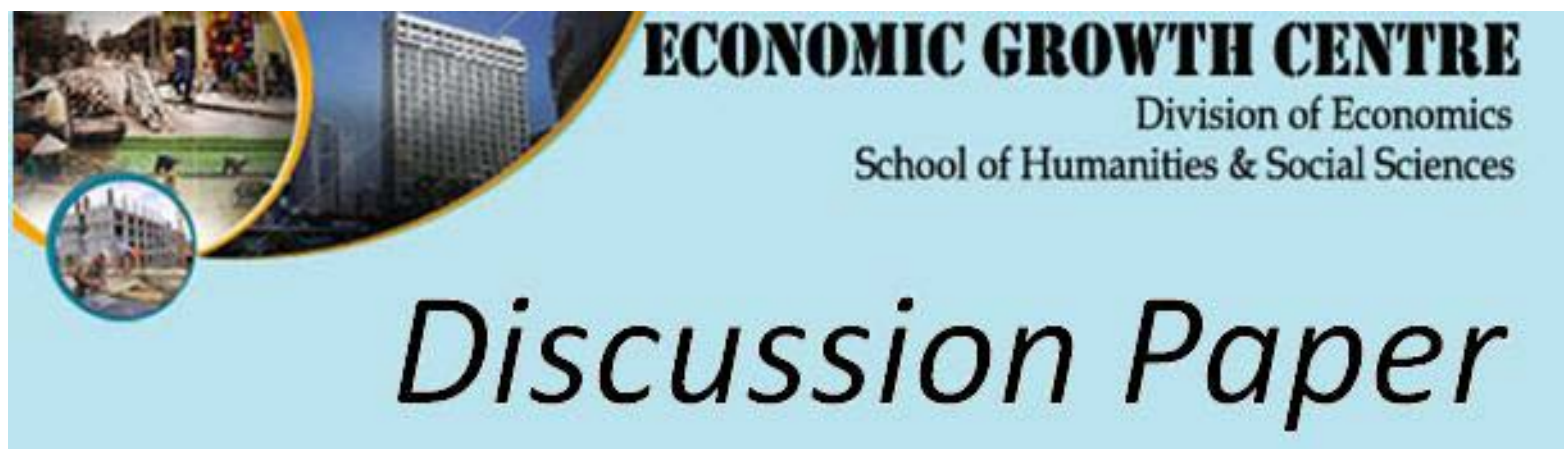


The author(s) bear sole responsibility for this paper.

Views expressed in this paper are those of the author(s) and not necessarily those of the Economic Growth Centre, NTU. 


\title{
Product Cycle, Contractibility and Global Sourcing
}

\author{
Xiaoping Chen, ${ }^{\mathrm{a}} \mathrm{Yi} \mathrm{Lu},{ }^{\mathrm{b}}$ and Lianming $\mathrm{Zhu}^{\mathrm{c}}$ \\ ${ }^{a}$ Nanyang Technological University, Singapore \\ b National University of Singapore, Singapore \\ ${ }^{\mathrm{c}}$ Kyoto University, Japan \\ This revision: February 2016
}

\begin{abstract}
This paper examines the organization structure of global sourcing over the product cycle. The paper combines a new product list dataset and China's customs data. The analysis finds that multinationals first produce within their foreign subsidiaries, and when the product matures, they start to outsource their production to external foreign suppliers. Global outsourcing appears later along the product cycle when the contractibility is better.
\end{abstract}

Keywords: Global sourcing; Product cycle; Contractibility; Difference-in-differencein-differences estimation

JEL Codes: F12, F23, L23, D23 


\section{Introduction}

International fragmentation has become a common strategy for firm organization of production. Using the data from ten OECD and four emerging market countries, Hummels, Ishii, and Yi (2001) document that international fragmentation of production accounted for 21 percent of exports in these countries in 1990 and explained more than 30 percent of the growth in exports between 1970 and 1990. Johnson and Noguera (2014) extend the analysis to 52 countries from 1970 to 2009, and find that the extent of international fragmentation increased by about 10 percentage points worldwide and the increase was much faster in the post-1990 period than in the pre-1990 period. Given this landscape change, an important question confronting researchers and practitioners is: how to organize global sourcing?

Antràs (2005) proposes a framework where the optimal choice of global sourcing strategies changes along the product cycle. Specifically, by incorporating the product cycle effect proposed by Vernon (1966) into the framework of production fragmented across borders with incomplete contracts, Antràs (2005) shows that along the product cycle, the manufacturing stage is first conducted in the home country where the product development takes place, then moved to low-wage foreign countries but within the firm's boundary, and finally outsourced to foreign external suppliers. However, other than anecdotal evidence and case studies, there is little systematic investigation of the product cycle effect on the choice of global sourcing strategies. Using new data on a new product list and a unique feature in China's trading system to measure global sourcing strategies, we provide the first analysis to quantify the product cycle effect on global sourcing.

Specifically, Xiang (2014) compiles a product list that classifies HS 10-digit products into the categories of new and old products. We match the list to China's customs data and differentiate each of the 5,000+ HS 6-digit products into new or old product groups. ${ }^{1}$ Meanwhile, China has a special trade regime - processing trade - that allows processing plants in China to import inputs free of tariffs but they must export all the output. Using the country identity of processing plants in China (i.e., foreign-owned or domestic-owned), we are able to distinguish the two types of global sourcing, i.e., global insourcing and global outsourcing. For details on the data, variable construction, and measurement issues, see section 3.

To isolate the product cycle effect on global sourcing from other non-product cycle effects, we compare the evolution of global sourcing strategies along the product cycle in China for firms from developed and developing countries among new and old products, a difference-indifference-in-differences (DDD) estimation strategy. As an illustration of and guidance for

\footnotetext{
${ }^{1}$ We are not able to do the analyses at the HS 10-digit level because the HS classification used in China is only comparable to that in the United States at the HS 6-digit level.
} 
our estimation strategy, in section 2, we extend the framework by Antràs (2005) to a setting of three countries, one home country and two foreign countries, in which foreign countries are considering their sourcing strategies in the home country.

We find that when a product matures, foreign multinationals in China start to outsource more of their manufacturing to external suppliers, consistent with the prediction by Antràs (2005). This pattern is born out in China Customs data from 1997 to 2011. These results are also robust to various checks on the classification of new products, the measurement of global sourcing strategies, and estimation specification.

While Antràs (2005) assumes a completely incomplete contract setting, we further extend the framework to incorporate the possibility that a fraction of components is contractible, following the framework in Antràs and Helpman (2008)'s work. We confirm that there is a similar sourcing pattern in this partially contractible framework, and further show that when the contractibility is better, global outsourcing appears later along the product cycle. We test and confirm this prediction using variations in the intensity of relationship-specific investment across industries (a measure constructed by Nunn, 2007).

Our study is related to the recent literature on the organization of multinationals (for reviews, see Antràs and Rossi-Hansberg, 2009; Yeaple, 2013; Antràs and Yeaple, 2014). In a seminal work, Antràs and Helpman (2004) use the property-rights framework to investigate how firms with different productivity levels choose their organizational structures, specifically, domestic versus global sourcing. ${ }^{2}$ This research framework has been expanded in several dimensions. For example, Du, Lu, and Tao (2009) and Schwarz and Suedekum (2014) further extend the theoretical framework to show the existence of hybrid sourcing structures, i.e., firms that outsource and produce their components in-house at the same time. Antràs and Chor (2013) consider how firms choose their organizational structures when their production entails multiple sequential stages. They show that the choice depends on the relationships among different production stages (complementary or substitute) and the location on the production chain (early versus late stages). Alfaro, Antràs, Chor, and Conconi (2015) further test this prediction based on Dun \& Bradstreet's (D\&B) WorldBase with firm production across 100 countries, and also show that the contractibility plays an important role in determining the organizational structures of firms. Our study follows the analysis by Antràs (2005), who considers the product cycle in the determination of global sourcing structures, and our contribution lies in being the first study to test the product cycle theory of global sourcing systematically.

Our study also contributes to the literature on product cycle theory proposed by Ver-

\footnotetext{
${ }^{2}$ Their theoretical findings are subsequently tested and confirmed by Yeaple (2006), Tomiura (2007), Corcos, Irac, Mion, and Verdier (2013), Defever and Toubal (2013), Nunn and Trefler (2013), and others.
} 
non (1966). Theoretical studies have explored how product cycles relate to trade patterns (Krugman 1979), innovation (Grossman and Helpman, 1991), and skill premium (Thoenig and Verdier, 2004; Zhu, 2004). Recent studies use data to test various predictions from these product cycle theories. For example, Feenstra and Rose (2000) test the product cycle theory by showing that developed countries export products earlier to the United States (U.S.) than to developing countries. Zhu (2005) tests whether skill upgrading in developed and developing countries since the 1970 s can be explained by product cycles (i.e., the relocation of U.S. production). To confront the product cycle theory more closely, Xiang (2014) constructs a product-level list of new products for U.S. manufacturing imports, and shows that the North's new product imports to the U.S., relative to the South's, exhibits an inverse-U shape over time, consistent with the prediction of the product cycle theory. Our study builds on Xiang (2014) to investigate the organization of multinationals over the product cycle.

\section{Model}

In this section, we build a simple model to illustrate firms' global sourcing decisions over the product cycle and to guide our empirical estimation. Specifically, we extend the framework by Antràs (2005) to include one more country as a control for non-product cycle factors affecting firms' global sourcing decisions in the empirical estimation.

\subsection{Basic Setup}

Consider a world with three countries (i.e., a home country $C$ and two foreign countries $N$ and $S$ ) and one production factor (i.e., labor). Consumers are infinitely lived and have identical preferences, which are given by

$$
U_{t}=\left(\sum_{j} y_{j t}^{\alpha}\right)^{1 / \alpha}, 0<\alpha<1
$$

where $t$ indicates period; $j$ indicates a product; $\alpha$ represents the constant elasticity of substitution among products; and $y_{j t}$ is the consumption of product $j$ at period $t$.

Given the utility function (1), we can derive the demand function for product $j$ at period $t$ as

$$
y_{j t}=\lambda_{t} p_{j t}^{-1 /(1-\alpha)}
$$

where $\lambda_{t} \equiv \frac{E_{t}}{\sum_{i} p_{i t}^{-\alpha /(1-\alpha)}}$ is taken as given by the firms; $E_{t}$ is total spending; and $p_{j t}$ is the price of product $j$ (inclusive of all trade costs). To save notation, we omit $j$ as cases are symmetric for all products. 
To produce any products, two product-specific inputs, $h$ and $m$, are jointly required, which are referred to as headquarters service (such as research and product development, marketing, etc.) and manufactured component, respectively. Correspondingly, there are two kinds of producers: final good producers (denoted by $H$ ), who provide the product-specific headquarters services $(h)$, and component makers (denoted by $M$ ), who supply the productspecific manufactured components $(m)$. Each unit of $h$ and $m$ requires one unit of labor. As our analysis primarily concerns sourcing patterns of foreign multinationals in China, we restrict final good producers to be located in either foreign country $N$ or $S$ (with the former having a higher wage rate than the latter, i.e., $w^{N}>w^{S}$ ), while component makers can be chosen domestically or from home country $C$ (whose wage is normalized to 1 ). ${ }^{3}$ Every final good producer organizes the production process by combining the headquarters service and the manufactured component in a Cobb-Douglas fashion to make the final product, i.e.,

$$
y_{t}=\gamma_{t} h_{t}^{1-z_{t}} m_{t}^{z_{t}}, 0 \leq z_{t} \leq 1
$$

where $\gamma_{t} \equiv z_{t}^{-z_{t}}\left(1-z_{t}\right)^{1-z_{t}}$; and $z_{t}$ is the key parameter in our analysis, which captures the extent of the product cycle and will be defined later.

Our data do not contain information on domestic sourcing outcomes by foreign multinationals (i.e., the production in their origin countries), but do contain information on their global sourcing outcomes (i.e., the production in China). Therefore, we assume that if the final good producer $H$ (from either country $N$ or $S$ ) sources the components in its origin country, it produces in-house (a mode referred to as headquarters manufacturing); but if it sources the components in country $C$, there are two options for organizing the components production: $H$ can contract with an external supplier in country $C$ for the supply of the manufactured component (a mode referred to as global outsourcing), or $H$ can set up its own subsidiary in country $C$ and make the component in-house (a mode referred to as global insourcing).

As in Antràs and Helpman (2004) and Antràs (2005), we consider a setting of incomplete contracts in the global sourcing scenario, which is especially the case in China given its weak contracting institutions. ${ }^{4}$ It is assumed that the precise nature of the required inputs is difficult to specify ex ante, and that, once revealed ex post, the nature of the required inputs is still not verifiable by a third party. It is further assumed that the ex ante investments for input production are not contractible and neither is the sales revenue. As a result, the

\footnotetext{
${ }^{3}$ We do not consider the case where country $N$ chooses a component maker from country $S$.

${ }^{4}$ In section 5, we consider a setting where a fraction of component can be perfectly contracted, and then test the predictions using variations in the intensity of relationship-specific investment across industries (a measure constructed by Nunn, 2007).
} 
final good producer $H$ and component supplier $M$ bargain over the surplus value from trade after they make their own inputs investments. Following the property-rights theory of the firm, we assume that the bargaining takes place in both outsourcing and insourcing and is modeled via the Nash bargaining framework with equal bargaining power for the two parties. Specifically, when the bargain fails in the outsourcing mode, both parties end up with nothing. However, in the case of insourcing, the final good producer $H$ can fire its component division manager $M$ and retain $\delta$ of the components if the bargain fails, whereas $M$ gets nothing after being fired. And we also assume $\delta^{\alpha} \leq 1 / 2$ as in Antràs (2005). ${ }^{5}$

\subsection{Product Cycle}

A crucial component of Vernon's (1966) product cycle theory is that as a good matures, it becomes more and more standardized. We follow Antràs (2005) in modeling this standardization process, i.e.,

$$
\begin{aligned}
z_{t} & =f(t), \text { with } f^{\prime}(t)>0, \\
f(0) & =0, \text { and } \lim _{t \rightarrow \infty} f(t)=1 .
\end{aligned}
$$

We differentiate four types of products in the model: (1) old or new products; and (2) products by final good producers from country $N$ or country $S$. Old products refer to those with substantial standardization, i.e., $t \rightarrow \infty$ and $z_{t} \rightarrow 1$, whereas new products are assumed to follow the standardization process (4) over time, i.e., $z_{t}=f(t)$ for new products. Meanwhile, old products in $N$ and $S$ are assumed to share similar features, but the standardization processes of new products in $N$ and $S$ are different. Specifically, we assume $z_{t}^{N}=f_{N}(t)$ to be first-order-stochastically dominated by $z_{t}^{S}=f_{S}(t)$; in other words, a new product matures faster when it is manufactured by a final good producer in country $N$ than in country $S$.

To illustrate this assumption, we provide a framework for a variety diffusion process following Xiang (2014), which is based on the literature of innovation diffusion (e.g., Trajtenberg and Yitzhaki, 1989; Hall and Kahn, 2003). There are multiple varieties of each product. And the product standardization process is a function of new varieties $m_{t}$ available at each point in time, i.e., $f_{N}(t)=f\left(m_{t}^{N}\right), f_{S}(t)=f\left(m_{t}^{S}\right)$. When a new product emerges in this world, the North and the South can immediately gain knowledge of this product and develop their own varieties over time. Let $t$ be the time, and $m_{t}^{N}$ and $m_{t}^{S}$ be the measure of new varieties that have diffused to country $N$ and country $S$ by time $t$, respectively. The

\footnotetext{
${ }^{5}$ This assumption is to ensure there is a single crossing between $A\left(z_{t}\right)$ and $A_{M}\left(z_{t}\right)$, which will be explained in detail in the next subsection. For more discussion and derivation of this assumption, see Antràs (2005).
} 
diffusion processes are assumed to be:

$$
\ln m_{t}^{N}=F_{N}(t) \ln \bar{m} ; \ln m_{t}^{S}=F_{S}(t) \ln \bar{m}
$$

where $\bar{m}$ is the asymptotic equilibrium measure of varieties for this product; $F_{N}(t)$ and $F_{S}(t)$ are two cumulative distribution functions over time. The product cycle hypothesis is incorporated by assuming that $F_{S}(t)$ first-order stochastically dominates $F_{N}(t)$, which means that the number of new varieties increases faster in country $N$ in the early period of the product cycle and country $S$ catches up in the middle or later period, reaching the same final equilibrium number of total varieties. The product standardization is assumed to accelerate with more varieties, i.e., $z$ is a monotonic increasing function of $m, z(m)^{\prime}>0$ and $z(m)^{\prime \prime}>0 .{ }^{6}$ Combined, we can have $f_{S}(t)$ first-order stochastically dominates $f_{N}(t)$.

\subsection{Firm Behavior}

Following Antràs (2005), from (2) and (3), the ex ante profit for the final good producer $H$ located in country $c \in\{N, S\}$ choosing headquarter manufacturing is given by $\pi_{c}^{H}\left(z_{t}\right)=$ $\lambda_{t}^{1-\alpha} \gamma_{t}^{\alpha} h_{t}^{\alpha\left(1-z_{t}\right)} m_{t}^{\alpha z_{t}}-w^{c} h_{t}-w^{c} m_{t}$. Solving for the optimal price for the final good, the profit for headquarter manufacturing is given by

$$
\pi_{c}^{H}\left(z_{t}\right)=(1-\alpha) \lambda_{t}\left(\frac{w^{c}}{\alpha}\right)^{-\alpha /(1-\alpha)} .
$$

For a final good producer choosing global outsourcing from an independent component producers in home country $C$, the Nash bargaining leaves each party with one-half of the total sales revenue $R_{t}=\lambda_{t}^{1-\alpha} \gamma_{t}^{\alpha} h_{t}^{\alpha\left(1-z_{t}\right)} m_{t}^{\alpha z_{t}}$. Solving for the optimal investment level of $h_{t}$ and $m_{t}$ for the final good producer and the component maker, respectively (and setting an ex ante transfer to make the component maker break even), we then have the ex ante profit for global outsourcing given by

$$
\pi_{c}^{A}\left(z_{t}\right)=\left(1-\frac{1}{2} \alpha\right) \lambda_{t}\left(\frac{2\left(w^{c}\right)^{1-z_{t}}}{\alpha}\right)^{-\alpha /(1-\alpha)} .
$$

For a final good producer choosing global insourcing in home country $C$, if the bargaining fails, the final good producer can fire the subsidiary manager and retain $\delta$ share of the output,

\footnotetext{
${ }^{6}$ We can simply assume that product standardization is an exogenous function of time. With successful standardization, an increase in $z$, is a Poisson arrival event for each variety-producing firm. Once the product is standardized for one variety, it immediately spills over to all existing varieties. Withn more varieties, there is naturally a higher probability of successful product standardization.
} 
which translates into sales revenue of $\delta^{\alpha} R$. Then the quasi-rent for the Nash bargaining is $\left(1-\delta^{\alpha}\right) R$. Solving for both parties' optimal investments $\left(h_{t}\right.$ and $\left.m_{t}\right)$ respectively (and setting an ex ante transfer to make the integrated subsidiary break even), we then have the ex ante profit for global insourcing given by

$$
\pi_{c}^{M}\left(z_{t}\right)=\left(1-\frac{1}{2} \alpha\left(1+\delta^{\alpha}\left(1-2 z_{t}\right)\right)\right) \lambda_{t}\left(\frac{2\left(w^{c}\right)^{1-z_{t}}}{\alpha\left(1+\delta^{\alpha}\right)^{1-z_{t}}\left(1-\delta^{\alpha}\right)^{z_{t}}}\right)^{-\alpha /(1-\alpha)}
$$

The optimal choice of production organization depends on the comparison among these three profit functions. Define the following variables for countries $N$ and $S$.

$$
\begin{aligned}
A\left(z_{t}\right) & =\left(\frac{1-\alpha}{\left(1-\frac{1}{2} \alpha\right)\left(\frac{1}{2}\right)^{\alpha /(1-\alpha)}}\right)^{(1-\alpha) /\left(\alpha z_{t}\right)} \\
A_{M}\left(z_{t}\right) & =\left(\frac{1-\alpha}{\left(1-\frac{1}{2} \alpha\left(1+\delta^{\alpha}\left(1-2 z_{t}\right)\right)\right.}\right)^{(1-\alpha) /\left(\alpha z_{t}\right)}\left(\frac{2}{\left(1+\delta^{\alpha}\right)^{1-z_{t}}\left(1-\delta^{\alpha}\right)^{z_{t}}}\right)^{1 / z_{t}} .
\end{aligned}
$$

We can show that there exists a unique cutoff $\bar{z}_{c}=A^{-1}\left(w^{c}\right)$ such that $\pi_{c}^{H}\left(z_{t}\right)>\pi_{c}^{A}\left(z_{t}\right)$ when $z_{t}<\bar{z}_{c} ; \pi_{c}^{H}\left(z_{t}\right)=\pi_{c}^{A}\left(z_{t}\right)$ when $z_{t}=\bar{z}_{c}$; and $\pi_{c}^{H}\left(z_{t}\right)<\pi_{c}^{A}\left(z_{t}\right)$ when $z_{t}>\bar{z}_{c}$. Meanwhile, it can also be shown that there exist a unique cutoff $\bar{z}_{c}^{M}=A_{M}^{-1}\left(w^{c}\right)$ such that $\pi_{c}^{H}\left(z_{t}\right)>\pi_{c}^{M}\left(z_{t}\right)$ when $z_{t}<\bar{z}_{c}^{M} ; \pi_{c}^{H}\left(z_{t}\right)=\pi_{c}^{M}\left(z_{t}\right)$ when $z_{t}=\bar{z}_{c}^{M}$; and $\pi_{c}^{H}\left(z_{t}\right)<\pi_{c}^{M}\left(z_{t}\right)$ when $z_{t}>\bar{z}_{c}^{M}$.

As shown in Antràs (2005), $A\left(z_{t}\right)$ and $A_{M}\left(z_{t}\right)$ decrease with $z_{t}$, and there exists a unique $\bar{z}^{A M}$, at which $A\left(\bar{z}^{A M}\right)=A_{M}\left(\bar{z}^{A M}\right)$. Meanwhile, $A\left(z_{t}\right)>A_{M}\left(z_{t}\right)$ when $z_{t}<\bar{z}^{A M}$; and $A\left(z_{t}\right)<A_{M}\left(z_{t}\right)$ when $z_{t}>\bar{z}^{A M}$. There are three mutually exclusive and exhaustive cases: (a) $\bar{z}_{c}=\bar{z}^{A M}=\bar{z}_{c}^{M}$; (b) $\bar{z}^{A M}<\bar{z}_{c}<\bar{z}_{c}^{M}$; and (c) $\bar{z}_{c}^{M}<\bar{z}_{c}<\bar{z}^{A M}$. Our following analysis focuses on case (c), as the mode of global insourcing is a dominated strategy in cases (a) and (b), which does not fit our empirical setting.

In the case of $\bar{z}_{c}^{M}<\bar{z}_{c}<\bar{z}^{A M}$, we have the following sourcing pattern in the equilibrium: (1) when $z_{t}<\bar{z}_{c}^{M}$, the final good producer chooses headquarter manufacturing; (2) when $\bar{z}_{c}^{M}<z_{t}<\bar{z}^{A M}$, the final good producer chooses global insourcing; and (3) when $\bar{z}^{A M}<z_{t}$, the final good producer chooses global outsourcing.

We now derive sourcing patterns for new and old products and for final good producers from country $N$ and country $S$ in country $C$. First, consider the patterns for old products. As old products have substantial standardization, or $z_{t} \rightarrow 1\left(>\bar{z}_{A M}\right.$ ), final good producers (from country $N$ and country $S$ ) will outsource their production of components to independent suppliers in country $C$.

For new products, the optimal choice of production organization depends on the standardization process defined in equation (4), which differs across country $N$ and country $S$. 
Denote $t_{c}^{M}=f_{c}^{-1}\left(\bar{z}_{c}^{M}\right)$ and $t_{c}^{A M}=f_{c}^{-1}\left(\bar{z}^{A M}\right)$, where $c \in\{N, S\}$. As $f_{N}^{-1}($.$) first-order sto-$ chastically dominates $f_{S}^{-1}\left(\right.$.) and $\bar{z}_{N}^{M}<\bar{z}_{S}^{M}$ (given that $w^{N}>w^{S}$ ), we have $t_{N}^{M}<t_{S}^{M}$ and $t_{N}^{A M}<t_{S}^{A M}$. We consider the case when $t_{S}^{M}<t_{N}^{A M}$; otherwise, before the final good producers from country $S$ move their component production to country $C$, the final good producers from country $N$ already outsource their component production in country $C$, which does not fit our empirical setting.

Figure 1 illustrates the sourcing pattern in the case of $t_{S}^{M}<t_{N}^{A M}$. Specifically, when $t>$ $t_{S}^{M}$, final good producers from country $N$ and country $S$ start the production of components in country $C$, or the process of global sourcing. And they both first produce the components within their own subsidiaries in country $C$ and when the new products mature, they then start to outsource the component production to independent firms in country $C$. Moreover, as the standardization process in country $N$ is faster than that in country $S$, for the same product, final good producers from country $N$ start the outsourcing in country $C$ earlier than their counterparts from country $S$.

[Insert Figure 1 Here]

\section{Estimation Strategy}

\subsection{Specification}

Outsourcing strategies in product $j$ from country $c$ in China can be summarized as follows. For new products, when $t_{c}^{M}<t<t_{c}^{A M}$, foreign firms produce in their subsidiaries in China; and when $t_{c}^{A M}<t$, foreign firms outsource to companies in China. Denote $y=1$ if foreign firms use insourcing in China; and 0 if foreign firms use outsourcing in China. Hence, $y_{j c t}=g_{c}(t)=I\left\{t: t_{c}^{M}<t<t_{c}^{A M}\right\}$ is a decreasing function of $t$, where $j \in J_{n} ; J_{n}$ is a set of new products; and $I$ is an indicator function. For old products, all foreign firms outsource in China; hence, $y_{j c t}=1$, where $j \in J_{o}$; and $J_{o}$ is the set of old products.

Empirically, we follow Xiang (2014) in dividing countries into two groups, the North and the South, and assume the standardization process is the same for all new products within the country group but differs across the two country groups. Specifically, as shown in Appendix Table A1, 31 countries whose average real per capita GDP in 1972-1996 exceeds $\$ 7,000$ are considered to be in the North group (e.g., the U.S., the U.K.), whereas the other 172 countries belong to the South group (e.g., Mexico, Indonesia). ${ }^{7}$

\footnotetext{
${ }^{7}$ To address the concern of round-trip foreign investment, we also experiment with the exclusion of Hong Kong and Macau from the analysis.
} 
To control for other non-product cycle factors that may determine the choice of global sourcing and linearizing the time function $g(t)$, we conduct a DDD estimation. Specifically, we use the following estimation equation

$$
y_{j c t}=\beta N e w_{j} \times N_{o r t h} \times H(t)+\lambda_{j t}+\lambda_{c t}+\lambda_{j c}+\varepsilon_{j c t},
$$

where $N e w_{j}$ indicates the new product; Nort $h_{c}$ indicates the group of North countries; $\lambda_{j t}$ is the product-time fixed effects, capturing those product-specific time varying determinants of sourcing strategies on top of the product cycle theory; $\lambda_{c t}$ is the country-time fixed effects, capturing those country-specific time varying determinants of sourcing strategies on top of the product cycle theory; $\lambda_{j c}$ is the product-country fixed effects, capturing those productcountry-specific time invariant determinants of sourcing strategies on top of the product cycle theory; and $\varepsilon_{p c t}$ is the i.i.d. error. Standard errors are clustered at the country-product level to deal with the potential serial correlation and heteroskedasticity issues (see Bertrand, Duflo, and Mullainathan, 2004).

$\beta$ is our parameter of interest, reflecting the product cycle effect identified in Figure 1. To illustrate our estimation strategy, consider the case of two products, old $(o)$ and new $(n)$, and two countries, North $(N)$ and South $(S)$. If we focus on the degree of global insourcing for the new product from the North, we have

$$
E\left[y_{n N t}\right]=\beta g_{N}(t)+\lambda_{n t}+\lambda_{N t}+\lambda_{n N}
$$

hence, the existence of other non-product cycle factors originated from the new product $\lambda_{n t}$, the country North $\lambda_{N t}$ and the product-North combination $\lambda_{n N}$ biases the estimate of product-cycle effect $\beta g_{N}(t)$ from $E\left[y_{n N t}\right]$. As shown in the result section, these non-productcycle factors are found to be quite prominent in the data.

To get rid of these non-product-cycle confounders, we add new products from the South and old products from the North and the South, i.e.,

$$
\begin{aligned}
E\left[y_{n S t}\right] & =\beta g_{S}(t)+\lambda_{n t}+\lambda_{S t}+\lambda_{n S} \\
E\left[y_{o N t}\right] & =\lambda_{o t}+\lambda_{N t}+\lambda_{o N} \\
E\left[y_{o S t}\right] & =\lambda_{o t}+\lambda_{S t}+\lambda_{o S} .
\end{aligned}
$$

Then we have

$$
E\left[y_{n N t}\right]-E\left[y_{n S t}\right]=\beta H(t)+\left(\lambda_{N t}-\lambda_{S t}\right)+\left(\lambda_{n N}-\lambda_{n S}\right),
$$


where $H(t) \equiv g_{N}(t)-g_{S}(t) ;$ and

$$
\left(E\left[y_{n N t}\right]-E\left[y_{n S t}\right]\right)-\left(E\left[y_{o N t}\right]-E\left[y_{o S t}\right]\right)=\beta H(t)+\left[\left(\lambda_{n N}-\lambda_{n S}\right)+\left(\lambda_{o N}-\lambda_{o S}\right)\right] .
$$

Given $\left(\lambda_{n N}-\lambda_{n S}\right)+\left(\lambda_{o N}-\lambda_{o S}\right)$ does not change over time, $\beta$ can be identified by checking the time trends of $\left(E\left[y_{n N t}\right]-E\left[y_{n S t}\right]\right)-\left(E\left[y_{o N t}\right]-E\left[y_{o S t}\right]\right)$. In other words, the first difference between the North and the South for the new product in equation (14) helps remove all product-specific factors common to both countries. And the second difference in equation (15) uses the difference between the North and the South for the old product to condition out all country-specific factors (common to both products) in the first difference (14). Finally, the time variation in (15) helps us control for time invariant differences in new and old products across the North and the South.

A complication introduced by our DDD estimation is that $H(t)$ is a non-monotonic function. Specifically, according to Figure 1, $H(t)$ takes the following form: 1) when $t_{S}^{M}<$ $t<t_{N}^{A M}, H(t)$ is flat (i.e., $\frac{\partial H(t)}{\partial t}=0$ ) as both North and South use insourcing for the new products in country $c$; 2) when $t_{N}^{A M}<t<\bar{t}, \frac{\partial H(t)}{\partial t}<0$ as the North starts the outsourcing of the new products in country $c$, while the South lags in such decision, where $\bar{t} \geq t_{S}^{A M}$ is the time when the speed of the outsourcing by the South outpaces that by the North and determined by comparison between $f_{N}^{-1}($.$) and f_{S}^{-1}($.$\left.) ; and 3\right)$ when $\bar{t}<t, \frac{\partial H(t)}{\partial t}>0$ as the South outsources more new products than the North in country $c$.

To capture this nonlinearity, we first estimate $H(t)$ nonparametrically. Specifically, we replace $H(t)$ with year dummies, and hence the estimation equation becomes

$$
y_{j c t}=\sum_{t} \boldsymbol{\beta}_{t} N e w_{j} \times N \operatorname{North}_{c} \times \lambda_{t}+\lambda_{j t}+\lambda_{c t}+\lambda_{j c}+\varepsilon_{j c t},
$$

where $\boldsymbol{\beta}_{t}$ is a vector of estimates corresponding to each year effect. Next, we use a parametric approximation of $H(t)$; specifically, a fourth-order time polynomial function, i.e.,

$$
y_{j c t}=\sum_{k=1}^{4} \boldsymbol{\beta}_{k} N e w_{j} \times N o r t h_{c} \times t^{k}+\lambda_{j t}+\lambda_{c t}+\lambda_{j c}+\varepsilon_{j c t} .
$$

Based on the parametric estimates $\boldsymbol{\beta}_{k}$, we are able to calculate the two turning points in the $H(t)$, i.e., $t_{S}^{M}$ and $\bar{t}$, which allows us to gauge the economic magnitudes. 


\subsection{Data and Variables}

Data. - Our empirical analysis combines two data sets. The first data set is a product list compiled by Xiang (2014) that classifies HS 10-digit products into the categories of new and old products. Specifically, Xiang (2014) spent over two years on matching the newly produced products in the U.S. from 1972 to 1987 that are identified by Xiang (2005) and classified at the SIC level to the HS 10-digit product categories contained in the imports data. For more details about the matching and examples of new products, see the online Appendix in Xiang (2014). Meanwhile, Xiang (2014) also discusses in detail the advantage of this method over the identification of new products through year-to-year changes in the numerical codes.

The second data set is China's customs data, starting from 1997 to 2011. The data set is at the product-destination-year level for the period of 1997-1999 and at the firm-productdestination-year level for the period of 2000-2011, covering the universe of all import and export transactions by Chinese exporters and importers. Specifically, it includes product information (at the HS 8-digit level), trade value, identity of Chinese importers and exporters, and import and export destinations.

New and Old Products. - As the HS coding systems in the U.S. and China are only comparable at the HS 6-digit level, we first match the two data sets at the HS 6-digit level and then classify each HS 6-digit product category into new or old products. Specifically, an HS 6-digit product category is classified as a new product if it contains at least one HS 10-digit new product. We find that 885 products can be classified as new products, and 4,243 belong to the old product group. Appendix Table A2 gives some examples about the new products and old products at the HS 6-digit level. Examples of new products are Microfilm, microfiche or other microform readers, Fused quartz laboratory, hygienic or pharmeutical war, Textured yarn nes, nylon, polyamide <50dtex not retai, etc. Meanwhile, examples of old products are Potatoes seed, fresh or chilled, Silica sands and quartz sands, Float glass etc sheets, absorbent or reflecting layer, etc. In the baseline estimation, we focus on a sample of products that existed in the first year of our sample period to alleviate the concern that product entry may drive and hence complicate the explanation of our estimates. In a robustness check, we include all newly entered products during the sample period.

However, one concern with this measurement of new products at the HS 6-digit level is that our list of new products may be over-sampled-e.g., an HS 6-digit new product consisted of mostly HS 10-digit old products and few HS 10-digit new products, which leads to an underestimation of our product cycle effect. As a robustness check, we use the percentage of HS 10-digit new products within an HS 6-digit product category as an 
alternative classification of new products at the HS 6-digit level.

Another concern with the new/old products measurement is that the list compiled by Xiang (2014) essentially identifies the products newly developed in the 1980s, around two decades earlier than our analysis period, raising the questions about whether new products already matures into old ones. However, as our model in Section 2 and Antràs (2005)'s show that when the new products are developed, firms first conduct the production in their home country. And the production is reallocated to the South once the product matures to a certain degree. Moreover, case studies in Antràs (2005) show that it takes around 18 years for the new product to mature enough for firms to reallocate their production to the South countries, which fits the timeline of our research setting. In other words, our sample period starts around the time that new products identified by Xiang (2014) become matured enough that foreign multinationals start to offshore in China, which then enables us to investigate the effect of product cycle on global sourcing structures using the data in China.

Global Sourcing Measurement. - To construct the measurement of the degree of outsourcing by foreign multinationals in China, we use a unique feature of China's trade system, the processing trade regime. When China adopted the "reform and opening" policy in 1978, it wanted to open its economy to attract new investment and technologies, but it also worried about the vulnerability of its already fragile domestic economy from the foreign competition. As a compromise, China only allowed import-processing firms (mostly foreign invested firms in China) to import materials free of tariffs and export all their outputs, the so-called processing trade regime. After three decades, processing trade continues to play a significant role in China. In 2005, processing trade accounted for about 57 percent of China's total exports and over 80 percent of exports by foreign invested firms in China. There are two types of processing trade, the pure-assembly regime and the import-and-assembly regime. ${ }^{8}$ Under the pure-assembly regime, a factory in China receives orders from, imports the materials supplied by, and delivers the processed outputs to its foreign client. Under the import-and-assembly regime, a factory in China imports materials from foreign suppliers and sells the processed outputs to foreign clients, both on its own account. And processing factories in China can be foreign-owned or indigenous. For more discussion on the processing trade regime in China, see Feenstra and Hanson (2005), Fernandes and Tang (2012), and Yu (2015).

The specific features of the processing trade regime provide us with the opportunity to measure the sourcing outcomes by foreign multinationals in China. Specifically, we assign

\footnotetext{
${ }^{8}$ In China's customs data, pure assembly trade is coded as "Processing and assembling" and the importand-assembly trade is coded as "Processing with imported materials". There are other types of processing trade regimes coded in the data, but they account for a very small portion of total trade.
} 
the case when a processing factory in China is foreign-owned to the global insourcing scenario, whereas the case with a Chinese domestic processing factory is assigned as the global outsourcing scenario (see Fernandes and Tang, 2012, for a similar approach). Then, we can calculate

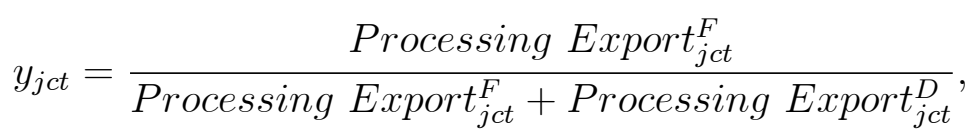

where Processing Export ${ }_{j c t}^{F}$ is the total value of processing exports by foreign-invested firms in China; and Processing Export ${ }_{j c t}^{D}$ is the total value of processing exports by Chinese domestic firms. Hence, $y_{j c t}$ captures the extent of insourcing in HS 6-digit product $j$ from country $c$ at year $t$.

\subsection{Identification Issues}

Our identification requires that conditional on all the fixed effects, the error term is uncorrelated with our regressor of interest, i.e., $\operatorname{cov}\left[N e w_{j} \times N\right.$ ort $\left.h_{c} \times H(t), \varepsilon_{j c t} \mid \lambda_{j t}, \lambda_{c t}, \lambda_{j c}\right]=0$ in equation (11). There are two possible threats to this identifying assumption - measurement errors associated with $y_{j c t}$ and omitted variables.

Measurement Error Problem.-Foreign multinationals may outsource the assembly to processing factories owned by other foreign multinationals in China, which is not observed due to our data limitation. Hence, the assignment of all foreign-owned processing factories to the global insourcing scenario may generate a measurement error in our outcome variable.

However, this measurement error problem is alleviated by the inclusion of full sets of fixed effects. For example, if the use of outsourcing to other foreign-owned processing factories in China is similar among foreign multinationals from the same country, the measurement error has been taken care of by the inclusion of the country-time fixed effects $\lambda_{c t}$ in equation (11). And if this strategy is similar in the same product category, the measurement problem has been addressed by the inclusion of the product-time fixed effects $\lambda_{j t}$ in equation (11). Meanwhile, if this strategy is country-product specific but does not change frequently over time (i.e., across years), the measurement problem is also controlled by the inclusion of the country-product fixed effects $\lambda_{j c}$ in equation (11). Lastly, if this strategy is country-product specific and changes frequently over time, it requires the measurement errors to follow a specific, nonlinear time trend to bias our estimate of $\beta$ in equation (11).

Omitted Variables Bias. - Even with the inclusion of flexible fixed effects, there could still exist some omitted variables (that vary at the country-product-year level) in our DDD estimation. A primary example is tariff rate; that is, China's different trading partners 
charge different product tariffs at different years. ${ }^{9}$ To address this concern, we add the country-product-year specific tariff rate in the analysis.

A Further Look and Placebo Test.-Here we take a closer look at the identification issue. Specifically, let $\varepsilon_{j c t}=\gamma \omega_{j c t}+v_{j c t}$, where $\omega_{j c t}$ captures all the omitted variables and measurement errors; and $v_{j c t}$ is the uncorrelated error. Then, estimation equation (11) becomes

$$
y_{j c t}=\beta N e w_{j} \times N_{o r t h} \times H(t)+\lambda_{j t}+\lambda_{c t}+\lambda_{j c}+\gamma \omega_{j c t}+v_{j c t},
$$

and our estimator $\hat{\beta}$ is

$$
\hat{\beta}=\beta+\gamma \delta,
$$

where $\delta \equiv \frac{\operatorname{cov}\left(N e w_{j} \times N o r t h_{c} \times H(t), \omega_{j c t} \mid \lambda_{j t}, \lambda_{c t}, \lambda_{j c}\right)}{\operatorname{var}\left(N e w_{j} \times N o r t h_{c} \times H(t) \mid \lambda_{j t}, \lambda_{c t}, \lambda_{j c}\right)}$. And $\hat{\beta} \neq \beta$ if $\gamma \delta \neq 0$.

As a further check on this identifying issue, we conduct a placebo test following Hanson and Xiang (2004) and Xiang (2014). Specifically, we randomly divide products into new or old product categories, and generate a false new product indicator, New false . The randomization ensures that $N e w_{j}^{\text {false }}$ should not have any product cycle effect on the organization of foreign multinationals, i.e. $\beta^{\text {false }}=0$; hence, if our DDD estimation is correctly specified (which implies $\gamma \delta=0$ ), we shall have $\hat{\beta}^{\text {false }}=0$. We conduct this random data-generating process 500 times to avoid contamination by any rare events (e.g., $\beta^{\text {false }} \neq 0$ ).

\section{Empirical Findings}

\subsection{Baseline Results}

We first estimate the time effect of $H(t)$ nonparametrically via the equation (16). The yearly estimated coefficients are plotted in Figure 2, together with the $95 \%$ confidence intervals. We find that the effect of product cycle is first flat, then declines and finally bottoms up. This pattern confirms the product cycle argument of global sourcing proposed by Antràs (2005); that is, at the early stage of product cycle, both the North and the South insource their production in China; when the product matures, the North first starts to outsourcing in China, and hence the estimated effects (which captures the difference of insourcing degrees between North and South multinationals) decline; and with further product maturing, the South also starts to outsource and its speed outpace the North's due to the catching up

\footnotetext{
${ }^{9}$ Note that as Chinese product tariffs are not discriminative across foreign countries, they have been controlled for by product-year fixed effects.
} 
effect, resulting in the increase of the estimated effects.

[Insert Figure 2 Here]

Column 1 of Table 1 presents the parametric estimation of $H(t)$ via the equation (17). We find that $N e w_{j} \times N$ orth $_{c} \times t$ is positive and statistically significant, $N e w_{j} \times N o r t h_{c} \times t^{2}$ is negative and statistically significant, $N e w_{j} \times N o r t h_{c} \times t^{3}$ is positive and statistically significant, and $N e w_{j} \times N o r t h_{c} \times t^{4}$ is negative and statistically significant. Figure 3 plots a fourth order polynomial of time effects based on these estimates. Similar to Figure 2, we have a first more stable period, followed by a sharp decline, and then an increase until stabilized again. Meanwhile, we calculate that the first turning point at 1.94, implying that after conducting businesses in China for about two years, North multinationals start to outsource their production to other firms in China. The second turning point is calculated as 6.58, which suggests that after around 7 years of maturing in China, the outsourcing by South multinationals catch up with that by North multinationals.

\section{[Insert Table 1 Here]}

[Insert Figure 3 Here]

We add the product tariffs imposed by China's trading partners in Table 1, column 2. Similar results are uncovered, in terms of both statistical significance and magnitude, suggesting that the pattern of product cycle on global outsourcing is not driven by the differential tariffs. To alleviate the concern that round trip FDI may drive our findings, we exclude Hong Kong and Macau in column 3 of Table 1. We find consistent results.

\subsection{Robustness Checks}

In this subsection, we present a battery of further robustness checks on our aforementioned estimation results.

Alternative Classification of New products at the HS 6-digit Level. - Due to the noncomparable coding systems between China's customs data and the new product lists compiled by Xiang (2014), we define the new product at the HS 6-digit level in our empirical analysis, and specifically, any HS 6-digit products with positive numbers of HS 10-digit new products are considered to be new products in the baseline estimation. This may raise concerns about whether our estimates are driven by the broad classification of new products at the HS 6digit level. As a robustness check, we use a continuous variable that captures the percentage 
of HS 10-digit new products within an HS 6-digit product. Estimation results are reported in Table 2, column 1. Evidently, we find similar pattern, implying that our findings are not affected by the classification of new products at the HS 6-digit level.

[Insert Table 2 Here]

Inclusion of Newly Entered Products. - Our baseline analyses focus on the products existed in the beginning of the sample period to alleviate the concern of product entry. As a robustness check, we use all products existed in the data, including product entries during the sample period. Estimation results are reported in Table 2, column 2. Clearly, we find similar estimates, suggesting that product entry does not bias our estimates.

A Placebo Test. - As a further check, we conduct a placebo test by randomizing the designation of new and old products. If our results are mostly explained by the misclassification of global sourcing strategies and other confounding factors, instead of the product cycle effect, we should expect similar negative and statistically significant effects for these randomized samples. We do the randomization 500 times, and report the average and standard deviation of these 500 estimates in column 3, Table 2. The average of our estimate of interest is found to be close to zero and highly insignificant, suggesting that our estimates are not driven by the misclassification of the sourcing strategies and other confounding factors.

\section{Global Sourcing over the Product Cycle with Con- tractibility}

Our baseline model in section 2 examines an incomplete contract setting where the ex ante investment in inputs is completely not contractible as ex post inputs are not verified by third parties. In this section, we extend the model to incorporate the possibility that a fraction of inputs can be contractible, and investigate how the contractibility affects the choice of global sourcing strategies over the product cycle. We then use the variations in relationship-specific investment intensity across industries (a measure constructed by Nunn, 2007) to test these predictions.

\subsection{Global Outsourcing with Contractibility}

We extend our baseline analysis to a partial-contractibility environment. Following Antràs and Helpman (2008), we assume that in an industry there is a fraction $\mu$ of activities that can be fully contracted (that is, its ex ante contract can be fully realized ex post); The 
rest of production activities are subject to the incomplete contract problem since they are relationship-specific. And this assumption applies to actions of component suppliers and final-good producers. ${ }^{10}$

As in Antràs and Helpman (2008), the equilibrium investment levels of contractible and noncontractible activities for final-good producers and component suppliers can be solved in a sub-game perfect equilibrium fashion. In equilibrium, the final good producer's profits with partial contractibility are given by ${ }^{11}$

$$
\begin{aligned}
& \pi_{c}^{\tilde{A}}\left(z_{t}\right) \\
= & (1-\alpha) \lambda_{t}\left[\alpha^{\alpha}\left(w^{c}\right)^{-\alpha\left(1-z_{t}\right)} \frac{\beta_{m}^{\alpha z_{t}(1-\mu)} \beta_{h}^{\alpha\left(1-z_{t}\right)(1-\mu)}\left(1-\alpha(1-\mu)\left[\beta_{m} z_{t}+\beta_{h}\left(1-z_{t}\right)\right]\right)^{1-\alpha(1-\mu)}}{(1-\alpha(1-\mu))^{1-\alpha(1-\mu)}}\right]^{1 /(1-\alpha)},
\end{aligned}
$$

where $\beta_{h}$ and $\beta_{m}$ are the equilibrium shares of claims on the total revenue for the final-good producer and component supplier, respectively. In the case of global outsourcing, we have $\beta_{m}=\beta_{h}=\frac{1}{2}$; in the case of global insourcing, we have $\beta_{h}=\frac{1}{2}\left(1+\delta^{\alpha}\right)$ and $\beta_{m}=\frac{1}{2}\left(1-\delta^{\alpha}\right)$.

\subsection{Equilibrium Choice and Comparative Statics}

Given the profit functions above for global outsourcing and global insourcing with partial contractibility, we can construct a new $\tilde{A}\left(z_{t}\right)$ and a new $\tilde{A}_{M}\left(z_{t}\right)$, respectively, corresponding to $A\left(z_{t}\right)$ and $A_{M}\left(z_{t}\right)$ defined in the previous sections. In particular, $A\left(z_{t}\right)$ and $A_{M}\left(z_{t}\right)$ are special cases of $\tilde{A}\left(z_{t}\right)$ and $\tilde{A}_{M}\left(z_{t}\right)$, respectively, when $\mu=0$.

It can be shown that $\tilde{A}\left(z_{t}\right)$ and $\tilde{A}_{M}\left(z_{t}\right)$ decrease with $z_{t}$; and $\tilde{A}_{M}\left(z_{t}\right)$ has a unique intersection with $\tilde{A}\left(z_{t}\right)$ from below. Denote the intersection of $\tilde{A}\left(z_{t}\right)$ and $\tilde{A}_{M}\left(z_{t}\right)$ by $\bar{z}^{\tilde{A} M}$. The equilibrium choice is qualitatively the same as that in Figure 1, but with different threshold points. ${ }^{12}$

As the contractibility $(\mu)$ varies across industries, optimal choices of global sourcing over the product cycle differ across industries. In particular, when investments are less contractible smaller $\mu$, global outsourcing becomes more prevalent and exists earlier over the product cycle. Thus, we have the following proposition:

Proposition 1. For any two industries $i, j$ with $\mu_{i}<\mu_{j}, \bar{z}_{i}^{\tilde{A} M}<\bar{z}_{j}^{\tilde{A} M}$.

Proof. See the Appendix.

\footnotetext{
${ }^{10}$ Our simplification from Antràs and Helpman (2008)'s is that we assume the same contractibility for suppliers' investment and final good producers' investment in a given industry.

${ }^{11}$ Please refer to Antràs and Helpman (2008) for more details in solving these investment levels.

${ }^{12}$ See the Appendix for the proof of this claim.
} 
This lemma shows that with better contractibility (higher $\mu$ ), global outsourcing appears at later stages over the product cycle. The intuition is that higher $\mu$ means that a smaller fraction of good production is subject to relationship-specific investment and there is less distortion due to incomplete contracts; hence, there are fewer incentives to outsource. This implies that ceteris paribus global outsourcing becomes less attractive and appears later in the product cycle if a larger faction of production activities becomes contractible.

\subsection{Empirical Test}

The empirical test of Proposition 1 encounters an additional issue. As elaborated in Section 3.1, to control for other non-product cycle factors, we use a DDD estimation, in which South countries and old products are used as control groups for the production of new products from North countries. However, a complication of such DDD estimation is that the time effect of product cycle on the outcome variable is non-monotonic, with two turning points (i.e., decline at the first turning point but increase at the second one).

Proposition 1 shows that for both North and South countries, $\bar{z}_{c}^{\tilde{A} M}$ shifts to the right in industries with better contractibility. As the first turning point $T_{1}$ happens at $t=f_{N}^{-1}\left(\bar{z}_{N}^{\tilde{A} M}\right)$, this means that in industries with better contractibility, $T_{1}$ happens later. However, the situation involving the second turning point $T_{2}$ is not straightforward as it requires the comparison between $f_{N}^{-1}($.$) and f_{S}^{-1}($.$) after t=f_{S}^{-1}\left(\bar{z}_{S}^{\tilde{A} M}\right)$. We formally derive the relations between contractibility and the two turning points (i.e., $T_{1}$ and $T_{2}$ ) in the following proposition.

Proposition 2. For products with better contractibility, $T_{1}$ appears later and $T_{2}$ appears earlier.

Proof. See the Appendix.

\subsection{Empirical Findings}

To test the predictions in the above propositions, we use the variations in contractibility across industries. Specifically, Nunn (2007) uses data from Rauch (1999), who classifies goods into three groups: goods traded on an organized exchange, goods that are reference priced in a trade publication, and goods that are neither sold on an exchange nor reference priced. Nunn (2007) constructs for each final goods $i$ the following two measures of the proportion of its intermediate inputs that are relationship-specific:

$$
R S_{i}=\sum_{j} \theta_{i j}\left(R_{j}^{\text {neither }}+R_{j}^{\text {refprice }}\right)
$$


where $\theta_{i j}$ is the proportion of input $j$ in the production of good $i$. $R_{j}^{\text {neither }}$ is the proportion of input $j$ that is neither sold on an organized exchange nor reference priced, and $R_{j}^{\text {refprice }}$ is the proportion of input $j$ that is reference priced. Nunn aggregates each of 4-digit SITC industry in the Rauch's origin classification to BEA's I-O industry classification of NAICS 1997 using concordance table from the U.S. Bureau of Economic Analysis (BEA). For estimation, we match the BEA's I-O industry level to the HS 10-digit product level and then aggregate HS 10-digit data to HS 6-digit data using the concordance table from the BEA.

For our analysis, we divide the sample into two, industries with high versus low contractibility, based on whether Nunn's (2007) index is above or below the sample median. Estimation results are reported in Table 3. Consistent with the prediction in Proposition 2, we find that the first turning point happens at later stage in industries with high contractibility than that in industries with low contractibility. Meanwhile, for the second turning point, high contractibility industries happens earlier than low contractibility ones. Combined, these results also confirm the result in Proposition 1-that is, global outsourcing appears at later stages over the product cycle when contractibility is better.

\section{Conclusion}

In this paper, we investigate the global sourcing pattern of foreign firms over the product cycle. Using data on processing firms in China, we identify foreign firms' sourcing strategy from Chinese processing plants as global insourcing, when they own the processing plants in China, and global outsourcing, when they source from independent processing plants in China. Using product-level trade data and a classification of new/old products, we then investigate foreign multinationals' sourcing strategies over the product cycle. We find strong support for the predictions in Antràs (2005) that when a product matures, foreign multinationals in China start to outsource more of their manufacturing to external suppliers.

While Antràs (2005) assumes a completely incomplete contract setting, we further extend the framework to incorporate the possibility that a fraction of components is contractible, following the framework by Antràs and Helpman (2008). We confirm a similar sourcing pattern in this partially contractible framework, and further show that when the contractibility is higher, global outsourcing appears later along the product cycle. We test and confirm this prediction using variations in the intensity of relationship-specific investment across industries.

Multinational firms' sourcing strategy, i.e. production organization, is a very important and comprehensive problem. We believe our results can help researchers and practitioners better understand this problem by showing the role of the product cycle and contractibility. 
Other factors that might affect sourcing strategies, such as the demand elasticity for different products, may be investigated in future research. 


\section{References}

[1] Alfaro, Laura, Pol Antràs, Davin Chor and Paola Conconi. 2015. "Internalizing Global Value Chains: A Firm-Level Analysis", NBER Working Paper No. 21582

[2] Antràs, Pol. 2005. "Incomplete Contracts and the Product Cycle", American Economic Review 95, 1054-1073

[3] Antràs, Pol and Davin Chor. 2013. "Organizing the Global Value Chain", Econometrica $81,2127-2204$

[4] Antràs, Pol and Elhanan Helpman. 2004. "Global Sourcing", Journal of Political Economy $112,552-580$

[5] Antràs, Pol and Elhanan Helpman. 2008. "Contractual Frictions and Global Sourcing", in The Organization of Firms in a Global Economy, ed. Elhanan Helpman, Dalia Marin, and Thierry Verdier, Cambridge, MA: Harvard University Press

[6] Antràs, Pol and Esteban Rossi-Hansberg. 2009. "Organizations and Trade", Annual Review of Economics 1, 43-64

[7] Antràs, Pol and Stephen R. Yeaple. 2014. "Multinational Firms and the Structure of International Trade", in Handbook of International Economics 4, ed. Gita Gopinath, Elhanan Helpman, and Ken Rogoff, Amsterdam: Elsevier

[8] Bertrand, Marianne, Esther Duflo, and Sendhil Mullainathan. 2004. "How Much Should We Trust Differences-in-Differences Estimates?", Quarterly Journal of Economics 19, $249-275$

[9] Corcos, Gregory, Delphine M. Irac, Giordano Mion, and Thierry Verdier. 2013. "The Determinants of Intrafirm Trade: Evidence from French Firms", Review of Economics and Statistics 95, 825-838

[10] Defever, Fabrice and Farid Toubal. 2013. "Productivity, Relationship-Specific Inputs and the Sourcing Modes of Multinationals", Journal of Economic Behavior \&3 Organization 94, 345-357

[11] Du, Julan, Yi Lu, and Zhigang Tao. 2009. "Bi-sourcing in the Global Economy", Journal of International Economics 77, 206-214

[12] Feenstra, Robert. 1998. "Integration of Trade and Disintegration of Production in the Global Economy", Journal of Economic Perspectives 12, 31-50 
[13] Feenstra, Robert and Gordon Hanson. 2005. "Ownership and Control in Outsourcing to China: Estimating the Property-Rights Theory of the Firm", Quarterly Journal of Economics, 729-761

[14] Feenstra, Robert and Andrew K. Rose. 2000. "Putting Things in Order: Trade Dynamics and Product Cycles", Review of Economics and Statistics 82, 369-385

[15] Fernandes, Ana and Heiwai Tang. 2012. "Determinants of Vertical Integration in Export Processing: Theory and Evidence from China", Journal of Development Economics 99, 396-414

[16] Grossman, Gene and Elhanan Helpman. 1991. Innovation and Growth in the Global Economy, Cambridge, MA: MIT Press

[17] Hall, Bronwyn H. and Beethika Khan. 2003. "Adoption of New Technology", in New Economy Handbook, ed. Jones Derek C., Academic Press.

[18] Hanson, Gordon H. and Chong Xiang. 2004. "The Home Market Effect and Bilateral Trade Patterns", American Economic Review 94, 1108-1112

[19] Hummels, David, Jun Ishii, and Kei-Mu Yi. 2001. "The Nature and Growth of Vertical Specialization in World Trade", Journal of International Economics 54, 75-96

[20] Johnson, Robert C. and Guillermo Noguera. 2014. "A Portrait of Trade in Value Added Over Four Decades", working paper

[21] Krugman, Paul. "A Model of Innovation, Technology Transfer and the World Distribution of Income", Journal of Political Economy 87, 253-266

[22] Nunn, Nathan. 2007. "Relationship-Specificity, Incomplete Contracts and the Pattern of Trade", Quarterly Journal of Economics 122, 569-600

[23] Nunn, Nathan and Daniel Trefler. 2013. "Incomplete Contracts and the Boundaries of the Multinational Firm", Journal of Economic Behavior \& Organization 94, 330-344

[24] Rauch, James E. 1999. "Networks versus Markets in International Trade", Journal of International Economics 48, 7-35

[25] Schwarz, Christian and Jens Suedekum. 2014. "Global Sourcing of Complex Production Processes", Journal of International Economics 93, 123-139

[26] Thoenig, Mathias and Thierry Verdier. 2003. "A Theory of Defensive Skill-Biased Innovation and Globalization", American Economic Review 93, 709-728 
[27] Tomiura, Eiichi. 2007. "Foreign Outsourcing, Exporting, and FDI: A Productivity Comparison at the Firm Level", Journal of International Economics 72, 113-127

[28] Trajtenberg, Manuel and Shlomo Yitzhaki. 1989. "The Diffusion of Innovations: A Methodological Reappraisal", Journal of Business $\&$ Economic Statistics 71, 35-47

[29] Vernon, Raymond. 1966. "International Investment and International Trade in the Product Cycle", Quarterly Journal of Economics 80, 190-207

[30] Xiang, Chong. 2005. "New Goods and the Relative Demand for Skilled Labor", Review of Economics and Statistics 87, 285-298

[31] Xiang, Chong. 2014. "Product Cycles in U.S. Imports Data", Review of Economics and Statistics 96, 999-1004

[32] Yeaple, Stephen R. 2006. "Offshoring, Foreign Direct Investment and the Structure of U.S. Trade", Journal of the European Economic Association 4, 602-611

[33] Yeaple, Stephen R. 2013. "The Multinational Firm", Annual Review of Economics 5, 193-217

[34] Yu, Miaojie. 2015. "Processing Trade, Tariff Reductions and Firm Productivity: Evidence from Chinese Firms", Economic Journal 125, 943-988.

[35] Zhu, Susan C. 2004. "Trade, Product Cycles and Inequality Within and Between Countries", Canadian Journal of Economics 37, 1042-1060

[36] Zhu, Susan C. 2005. "Can Product Cycles Explain Skill Upgrading", Journal of International Economics 66, 131-155 


\section{Appendix A: Proof of Proposition 1}

First we show that $\tilde{A}_{M}\left(z_{t}\right)$ intersects with $\tilde{A}\left(z_{t}\right)$ from below at a unique $z$. It is equivalent to show that profit under global outsourcing increases from below and exceeds that under global insourcing. This part of the proof is very similar to the proof of Lemma 2 in Antràs (2005).

Define $\Omega\left(z_{t}\right)=\left(\pi_{c O}^{\tilde{A}}\left(z_{t}\right) / \pi_{c V}^{\tilde{A}}\left(z_{t}\right)\right)^{1-\alpha}$, where $\pi_{c O}^{\tilde{A}}\left(z_{t}\right)$ is the final good producer's profit under global outsourcing and $\pi_{c V}^{\tilde{A}}\left(z_{t}\right)$ is the profit for the final good producer under global insourcing.

We then have

$$
\Omega\left(z_{t}\right)=\frac{1}{\left(1-\delta^{\alpha}\right)^{\alpha z_{t}(1-\mu)}\left(1+\delta^{\alpha}\right)^{\alpha\left(1-z_{t}\right)(1-\mu)}} \frac{\left(1-\frac{\alpha}{2}(1-\mu)\right)^{1-\alpha(1-\mu)}}{\left\{1-\frac{\alpha}{2}\left[1+\delta^{\alpha}\left(1-2 z_{t}\right)\right](1-\mu)\right\}^{1-\alpha(1-\mu)}} .
$$

Taking the natural $\log$ of $\Omega\left(z_{t}\right)$ and the derivative with respect to $z_{t}$, we have

$$
\frac{\partial \ln \Omega\left(z_{t}\right)}{\partial z_{t}}=\alpha(1-\mu) \ln \left(\frac{1+\delta^{\alpha}}{1-\delta^{\alpha}}\right)-\frac{[1-\alpha(1-\mu)] \alpha(1-\mu) \delta^{\alpha}}{1-\frac{\alpha}{2}\left[1+\delta^{\alpha}\left(1-2 z_{t}\right)\right](1-\mu)} .
$$

Thus $\Omega^{\prime}\left(z_{t}\right)>0$ if and only if

$$
\ln \left(\frac{1+\delta^{\alpha}}{1-\delta^{\alpha}}\right)>\frac{[1-\alpha(1-\mu)] \delta^{\alpha}}{1-\frac{\alpha}{2}\left[1+\delta^{\alpha}\left(1-2 z_{t}\right)\right](1-\mu)} .
$$

The right-hand side is decreasing in $z_{t}$ and is therefore no larger than $[1-\alpha(1-\mu)] \delta^{\alpha} /[1-$ $\left.\frac{\alpha}{2}\left[1+\delta^{\alpha}\right](1-\mu)\right]$, which can be shown to be smaller than $\ln \left[\left(1+\delta^{\alpha}\right)\left(1-\delta^{\alpha}\right)\right.$. To see this, simply define $f(\delta)=\ln \left[\left(1+\delta^{\alpha}\right)\left(1-\delta^{\alpha}\right)-[1-\alpha(1-\mu)] \delta^{\alpha} /\left[1-\frac{\alpha}{2}\left[1+\delta^{\alpha}\right](1-\mu)\right]\right.$ and notice that $f(\delta)$ is increasing in $\delta$ and satisfies $f(0)=0$. We thus conclude that $\Omega^{\prime}\left(z_{t}\right)>0$ for all $z_{t} \in[0,1]$.

Next, it can be easily verified that $\Omega(0)<1$ and $\Omega(1)>1$, hence there exists a unique $\bar{z}^{\tilde{A} M}$ such that $\tilde{A}\left(z_{t}\right)>\tilde{A}_{M}\left(z_{t}\right)$ for all $0<z<\bar{z}^{\tilde{A} M}$ and $\tilde{A}\left(z_{t}\right)<\tilde{A}_{M}\left(z_{t}\right)$ for $\bar{z}^{\tilde{A} M}<z<1$.

Now we show that a smaller value of $\mu$ will generate a smaller cutoff $\bar{z}^{\tilde{A} M}$. It is sufficient to show that $\frac{\partial^{2} \ln \Omega\left(z_{t}\right)}{\partial z_{t} \partial \mu}<0$.

Taking the second-order derivative with respect to $\mu$ gives

$$
\begin{gathered}
\frac{\partial^{2} \ln \Omega\left(z_{t}\right)}{\partial z_{t} \partial \mu}=-\alpha \ln \left(\frac{1+\delta^{\alpha}}{1-\delta^{\alpha}}\right)+\frac{\alpha \delta^{\alpha}[1-2 \alpha(1-\mu)]}{1-\frac{\alpha}{2}\left[1+\delta^{\alpha}\left(1-2 z_{t}\right)\right](1-\mu)} \\
+\frac{\alpha \delta^{\alpha}[1-\alpha(1-\mu)] \frac{\alpha}{2}\left[1+\delta^{\alpha}\left(1-2 z_{t}\right)\right](1-\mu)}{\left[1-\frac{\alpha}{2}\left[1+\delta^{\alpha}\left(1-2 z_{t}\right)\right](1-\mu)\right]^{2}} .
\end{gathered}
$$


The second and third term are decreasing in $z_{t}$, then

$$
\begin{aligned}
\frac{\partial^{2} \ln \Omega\left(z_{t}\right)}{\partial z_{t} \partial \mu} \leq & -\alpha \ln \left(\frac{1+\delta^{\alpha}}{1-\delta^{\alpha}}\right)+\frac{\alpha \delta^{\alpha}[1-2 \alpha(1-\mu)]}{1-\frac{\alpha}{2}\left[1+\delta^{\alpha}\right](1-\mu)}+\frac{\alpha \delta^{\alpha}[1-\alpha(1-\mu)] \frac{\alpha}{2}\left[1+\delta^{\alpha}\right](1-\mu)}{\left[1-\frac{\alpha}{2}\left[1+\delta^{\alpha}\right](1-\mu)\right]^{2}} . \\
R H S= & \alpha\left\{-\ln \left(\frac{1+\delta^{\alpha}}{1-\delta^{\alpha}}\right)+\frac{\delta^{\alpha}[1-2 \alpha(1-\mu)]+\delta^{\alpha} \alpha(1-\mu) \frac{\alpha}{2}\left[1+\delta^{\alpha}\right](1-\mu)}{\left[1-\frac{\alpha}{2}\left[1+\delta^{\alpha}\right](1-\mu)\right]^{2}}\right\} \\
= & \alpha\left\{-\ln \left(\frac{1+\delta^{\alpha}}{1-\delta^{\alpha}}\right)+\frac{\delta^{\alpha}[1-\alpha(1-\mu)]+\delta^{\alpha} \alpha(1-\mu)\left[-1+\frac{\alpha}{2}\left[1+\delta^{\alpha}\right](1-\mu)\right]}{\left[1-\frac{\alpha}{2}\left[1+\delta^{\alpha}\right](1-\mu)\right]^{2}}\right\} \\
= & \alpha\left\{-\ln \left(\frac{1+\delta^{\alpha}}{1-\delta^{\alpha}}\right)-\frac{\delta^{\alpha} \alpha(1-\mu)}{1-\frac{\alpha}{2}\left[1+\delta^{\alpha}\right](1-\mu)}+\frac{\delta^{\alpha}[1-\alpha(1-\mu)]}{\left[1-\frac{\alpha}{2}\left[1+\delta^{\alpha}\right](1-\mu)\right]^{2}}\right\}
\end{aligned}
$$

As shown earlier, $\ln \left[\left(1+\delta^{\alpha}\right)\left(1-\delta^{\alpha}\right)>[1-\alpha(1-\mu)] \delta^{\alpha} /\left[1-\frac{\alpha}{2}\left[1+\delta^{\alpha}\right](1-\mu)\right]\right.$, so we have

$$
\begin{aligned}
\frac{1}{\alpha} R H S & \leq-\frac{[1-\alpha(1-\mu)] \delta^{\alpha}}{1-\frac{\alpha}{2}\left[1+\delta^{\alpha}\right](1-\mu)}-\frac{\delta^{\alpha} \alpha(1-\mu)}{1-\frac{\alpha}{2}\left[1+\delta^{\alpha}\right](1-\mu)}+\frac{\delta^{\alpha}[1-\alpha(1-\mu)]}{\left[1-\frac{\alpha}{2}\left[1+\delta^{\alpha}\right](1-\mu)\right]^{2}} \\
& =-\frac{\delta^{\alpha}}{1-\frac{\alpha}{2}\left[1+\delta^{\alpha}\right](1-\mu)}+\frac{\delta^{\alpha}[1-\alpha(1-\mu)]}{\left[1-\frac{\alpha}{2}\left[1+\delta^{\alpha}\right](1-\mu)\right]^{2}} \\
& =-\frac{\delta^{\alpha}\left(1-\frac{\alpha}{2}\left[1+\delta^{\alpha}\right](1-\mu)-[1-\alpha(1-\mu)]\right)}{\left[1-\frac{\alpha}{2}\left[1+\delta^{\alpha}\right](1-\mu)\right]^{2}}=-\frac{\delta^{\alpha} \alpha(1-\mu)\left(1-\frac{1+\delta^{\alpha}}{2}\right)}{\left[1-\frac{\alpha}{2}\left[1+\delta^{\alpha}\right](1-\mu)\right]^{2}}
\end{aligned}
$$

Given $\delta^{\alpha}<1$, we have $\frac{1}{\alpha} R H S \leq 0$. We thus conclude that $\frac{\partial^{2} \ln \Omega\left(z_{t}\right)}{\partial z_{t} \partial \mu}<0$. As a result, for an industry with a smaller $\mu$, global outsourcing dominates global insourcing earlier than other industries. Proposition 1 is thus proved.

\section{Appendix B: Proof of Proposition 2}

Our analysis focuses on the new products, i.e., $j \in J_{n}$ where $J_{n}$ is a set of new products.

The first part of the proposition that $T_{1}$ appears later for products with better contractibility directly follows Proposition 1 that products with better contractibility switch to outsourcing at a higher mature level.

For the second turning point $T_{2}$, it appears when $y_{j S t}$ decreases faster than $y_{j N t}$, where $y_{j c t}=X_{j c t}^{I} /\left(X_{j c t}^{I}+X_{j c t}^{O}\right)$ and $c \in\{N, S\}$. Here, denote by $X^{I}$ the pattern of global insourcing, and by $X^{O}$ that of global outsourcing. In other words, at $T_{2}$, we have $d y_{j N t} / d t=d y_{j S t} / d t$. 
Consider another product $j^{\prime}$ with higher contractibility, firms postpone the outsourcing strategy, thus the absolute quantity of global insourcing firms are larger for this product in both North and South at any point of time after $t>T_{1}^{\prime}>T_{1}$, i.e. $X_{j^{\prime} N t}^{I}>X_{j N t}^{I}$ and $X_{j^{\prime} S t}^{I}>X_{j S t}^{I}$. Additionally, the difference is larger for the North, $X_{j^{\prime} N t}^{I}-X_{j N t}^{I}>X_{j^{\prime} S t}^{I}-X_{j S t}^{I}$, because product varieties mature faster in the North and more of them adopt global insourcing before reaching $\bar{z}_{j^{\prime}}^{\tilde{A} M}$. The arise of global outsourcing triggers the decrease of global insourcing shares $y_{j N t}$ and $y_{j S t}$. For product $j$, we need $d X_{j S t}^{O} d t$ to be large enough relative to $d X_{j N t}^{O} d t$ in order for the outsourcing share change in the South to catch up with that in the North. Now in order for $d y_{j^{\prime} S t} / d t$ to catch up (in absolute values) with $d y_{j^{\prime} N t} / d t / d t$, we only need a smaller $d X_{j^{\prime} S t}^{O} d t$ relative to $d X_{j^{\prime} N t}^{O} d t$, since $X_{j^{\prime} N t}^{I}$ increases more than $X_{j^{\prime} S t}^{I}$. Given the assumption of the same variety diffusion (or product maturation) process for all products, we have $d X_{j N t}^{O} d t=d X_{j^{\prime} N t}^{O} d t$ after $t>\max \left\{T_{1}, T_{1}^{\prime}\right\}$. Only a smaller relative speed of product maturation is needed for the South to catch up in outsourcing share, thus the occurrence for the second turning point will be earlier, $T_{2}^{\prime}<T_{2}$. 
Figure 1 Global sourcing over the product cycle

\begin{tabular}{|c|c|c|}
\hline South firms: & Global is & Global outsourc \\
\hline North firms: & Global insourcing & Global outsourcing \\
\hline
\end{tabular}


Figure 2 Nonparametric estimation

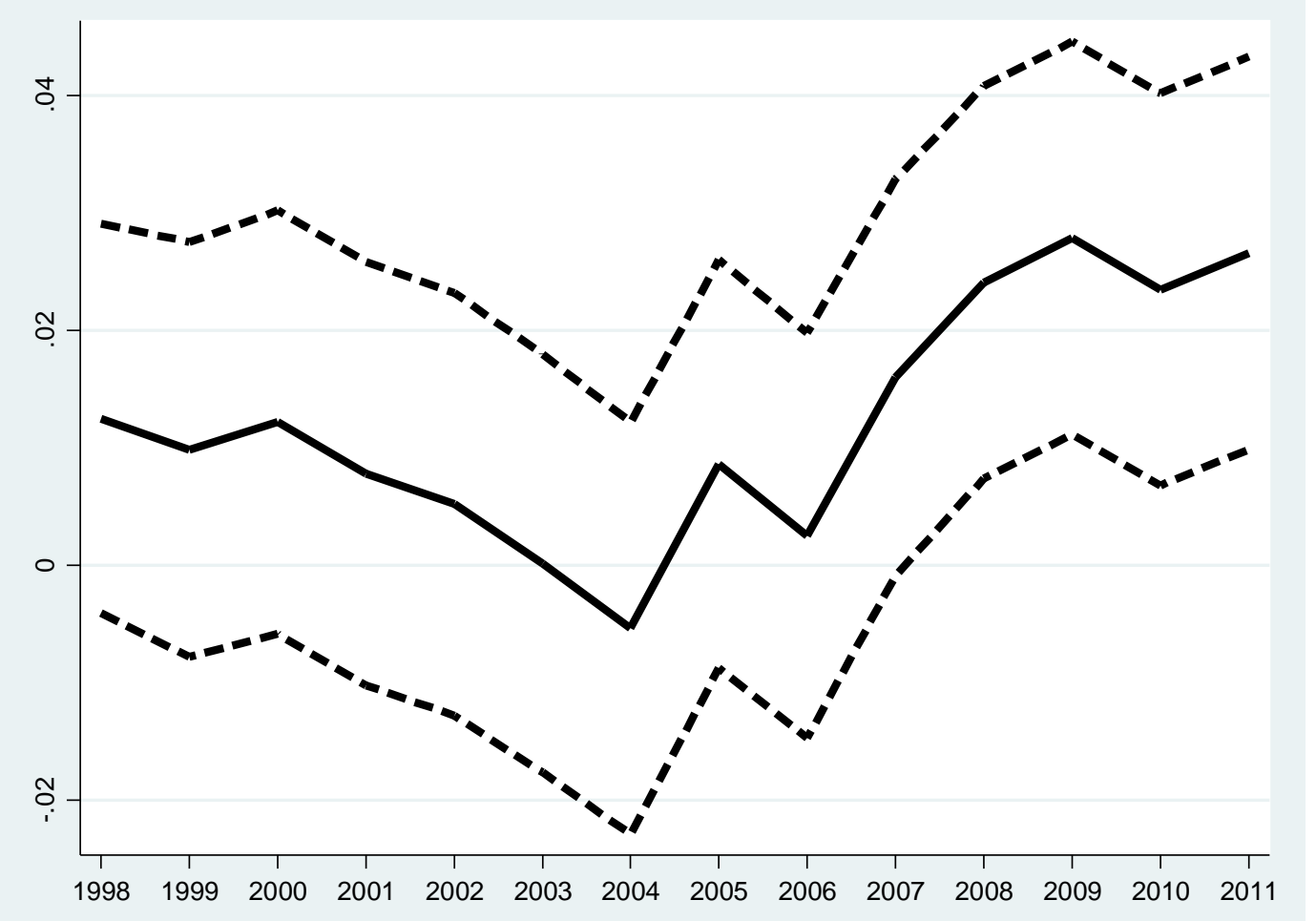


Figure 3 Parametric estimation

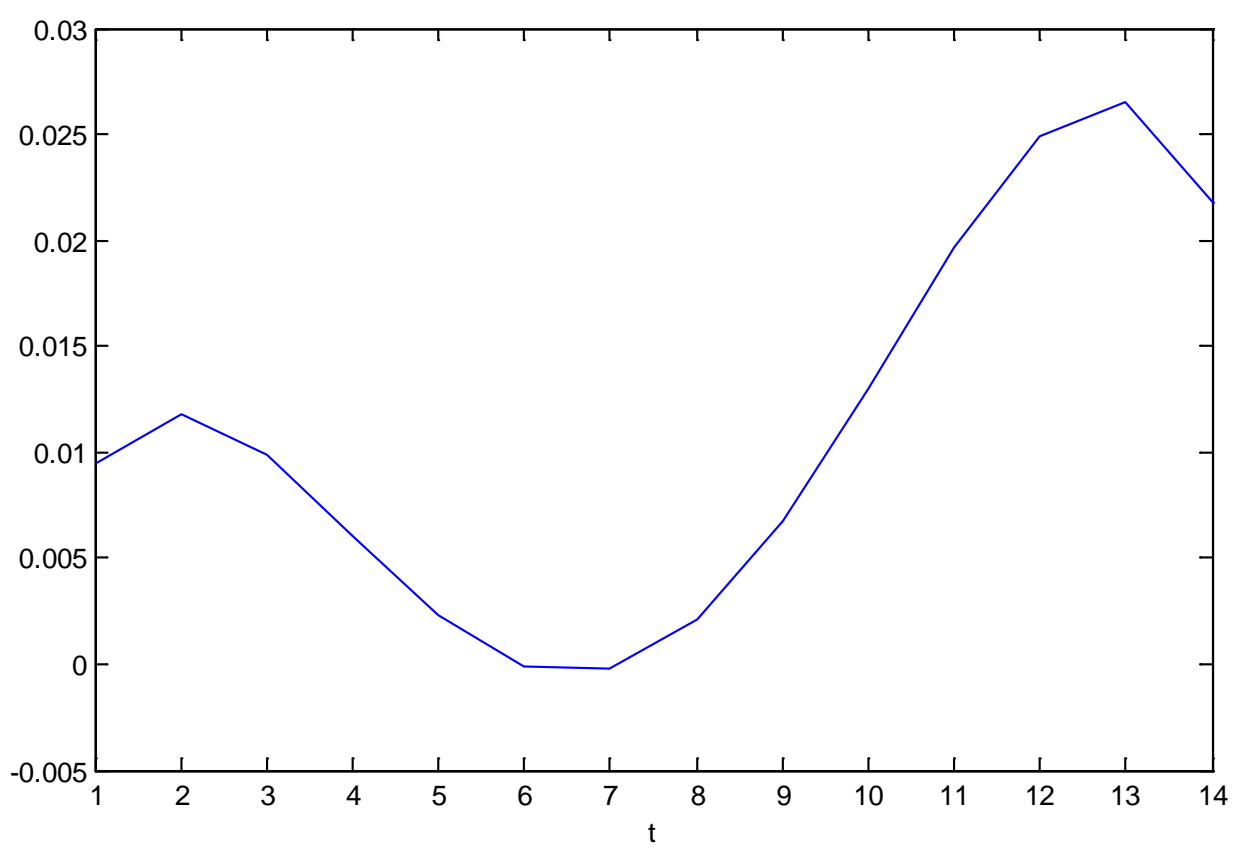


Table 1 Main results

\begin{tabular}{lccc}
\hline \hline Dependent variable: Insourcing share & Full sample & Full sample & $\begin{array}{c}\text { Hong Kong and } \\
\text { Macau excluded }\end{array}$ \\
\hline New $\times$ North $\times t$ & $(1)$ & $(2)$ & $(3)$ \\
New $\times$ North $\times t^{2}$ & $0.0141^{* *}$ & $0.0137^{* *}$ & $0.0175^{* *}$ \\
& $(0.00615)$ & $(0.00682)$ & $(0.00709)$ \\
New $\times$ North $\times t^{3}$ & $-0.00525^{* * *}$ & $-0.00499^{* * *}$ & $-0.00579^{* * *}$ \\
& $(0.00174)$ & $(0.00191)$ & $(0.00198)$ \\
New $\times$ North $\times t^{4}$ & $0.000612^{* * *}$ & $0.000572^{* * *}$ & $0.000636^{* * *}$ \\
& $(0.000179)$ & $(0.000195)$ & $(0.000202)$ \\
Tariffs & $-0.0000215^{* * *}$ & $-0.0000198^{* * *}$ & $-0.0000216^{* * *}$ \\
& $(0.00000604)$ & $(0.00000653)$ & $(0.00000675)$ \\
T1 & & $0.000366^{* * *}$ & $0.000378^{* * *}$ \\
T2 & 1.94 & $(0.000137)$ & $(0.000140)$ \\
\hline Product-year fixed effects & 6.58 & 1.99 & 2.28 \\
Country-year fixed effects & Yes & 6.68 & 6.88 \\
Product-country fixed effects & Yes & Yes & Yes \\
\hline Observations & Yes & Yes & Yes \\
\hline \hline Note: Standar & $1,539,180$ & $1,262,131$ & $1,208,644$ \\
\hline
\end{tabular}

Note: Standard errors are clustered at the product-country level. ***,** and * denote significance at the 1,5 and $10 \%$ level respectively. 
Table 2 Robustness checks

\begin{tabular}{|c|c|c|c|}
\hline Dependent variable: Insourcing share & New products ratio & $\begin{array}{l}\text { Newly entered products } \\
\text { included }\end{array}$ & Placebo test \\
\hline & (1) & (2) & (3) \\
\hline \multirow[t]{2}{*}{ New $\times$ North $\times t$} & 0.0112 & $0.0166^{* *}$ & -0.000051 \\
\hline & $(0.00983)$ & $(0.00709)$ & $(0.0083713)$ \\
\hline \multirow[t]{2}{*}{ New $\times$ North $\times t^{2}$} & $-0.00526^{*}$ & $-0.00549 * * *$ & 0.0000738 \\
\hline & $(0.00273)$ & $(0.00197)$ & $(0.0023217)$ \\
\hline \multirow[t]{2}{*}{ New $\times$ North $\times t^{3}$} & $0.000617 * *$ & $0.000605 * * *$ & -0.0000121 \\
\hline & $(0.000278)$ & $(0.000201)$ & $(0.000236)$ \\
\hline \multirow[t]{2}{*}{ New $\times$ North $\times t^{4}$} & $-0.0000213^{* *}$ & $-0.0000206^{* * *}$ & 0.0000005 \\
\hline & $(0.00000931)$ & $(0.00000673)$ & $(0.00000789)$ \\
\hline \multirow[t]{2}{*}{ Tariffs } & $0.000375 * * *$ & $0.000391 * * *$ & $0.0003745^{* * *}$ \\
\hline & $(0.000140)$ & $(0.000139)$ & $(0.0001397)$ \\
\hline $\mathrm{T} 1$ & 1.38 & 2.29 & - \\
\hline $\mathrm{T} 2$ & 7.33 & 6.82 & - \\
\hline Product-year fixed effects & Yes & Yes & Yes \\
\hline Country-year fixed effects & Yes & Yes & Yes \\
\hline Product-country fixed effects & Yes & Yes & Yes \\
\hline Observations & $1,208,644$ & $1,242,125$ & $1,208,644$ \\
\hline
\end{tabular}

Note: Standard errors are clustered at the product-country level. $* * *, * *$ and $*$ denote significance at the 1,5 and $10 \%$ level respectively. 
Table 3 Heterogeneous effects across contractibility

\begin{tabular}{lcc}
\hline \hline Dependent variable: Insouring share & High contractibility & Low contractibility \\
\hline New $\times$ North $\times t$ & $0.0255^{* *}$ & $(2)$ \\
& $(0.0124)$ & $0.0195^{* *}$ \\
New $\times$ North $\times t^{2}$ & $-0.00687^{* *}$ & $(0.00911)$ \\
& $(0.00345)$ & $-0.00605^{* *}$ \\
New $\times$ North $\times t^{3}$ & $0.000703^{* *}$ & $(0.00254)$ \\
& $(0.000351)$ & $0.000630^{* *}$ \\
New $\times$ North $\times t^{4}$ & $-0.0000232^{* *}$ & $(0.000259)$ \\
& $(0.0000118)$ & $-0.0000208^{* *}$ \\
Tariffs & -0.000119 & $(0.00000868)$ \\
& $(0.000187)$ & $0.00103^{* * *}$ \\
T1 & 3.23 & $(0.000243)$ \\
T2 & 6.60 & 2.44 \\
\hline Product-year fixed effects & Yes & 7.52 \\
Country-year fixed effects & Yes & Yes \\
Product-country fixed effects & Yes & Yes \\
\hline Observations & 597,577 & Yes \\
\hline \hline
\end{tabular}

Note: Standard errors are clustered at the product-country level. $* * *, * *$ and $*$ denote significance at the 1,5 and $10 \%$ level respectively. 
Appendix Table A1 Country list

\begin{tabular}{|c|c|c|c|c|c|c|}
\hline \multicolumn{7}{|c|}{ List of North countries } \\
\hline Australia & Austria & Bahamas, The & Bahrain & Belgium & Canada & Denmark \\
\hline Finland & France & Germany & Hong Kong & Iceland & Ireland & Israel \\
\hline Italy & Japan & Kuwait & Netherlands & New Zealand & Norway & Qatar \\
\hline Saudi Arabia & Singapore & Spain & Sweden & Switzerland & $\begin{array}{l}\text { Trinidad and } \\
\text { Tobago }\end{array}$ & $\begin{array}{l}\text { United Arab } \\
\text { Emirates }\end{array}$ \\
\hline United Kingdom & United States & Venezuela & & & & \\
\hline \multicolumn{7}{|c|}{ List of South countries } \\
\hline Afghanistan & Albania & Algeria & Angola & Andorra & $\begin{array}{l}\text { Antigua and } \\
\text { Barbuda }\end{array}$ & Argentina \\
\hline Armenia & Aruba & Azerbaijan & Bangladesh & Barbados & Belarus & Belize \\
\hline Benin & Bhutan & Bolivia & $\begin{array}{l}\text { Bosnia and } \\
\text { Herzegovina }\end{array}$ & Botswana & Brazil & Brunei \\
\hline Bulgaria & Burkina Faso & Burma & Burundi & Cambodia & Cameroon & Cape Verde \\
\hline $\begin{array}{c}\text { Central African } \\
\text { Republic }\end{array}$ & Chad & Chile & Colombia & Comoros & $\begin{array}{c}\text { Congo, } \\
\text { Democratic } \\
\text { Republic of the }\end{array}$ & $\begin{array}{c}\text { Congo, Republic } \\
\text { of the }\end{array}$ \\
\hline Costa Rica & Cote d'Ivoire & Croatia & Cuba & Curacao & Cyprus & Czech Republic \\
\hline Djibouti & Dominica & $\begin{array}{l}\text { Dominican } \\
\text { Republic }\end{array}$ & Ecuador & Egypt & El Salvador & $\begin{array}{l}\text { Equatorial } \\
\text { Guinea }\end{array}$ \\
\hline Eritrea & Estonia & Ethiopia & Fiji & Gabon & Gambia, The & Georgia \\
\hline Ghana & Greece & Grenada & Guatemala & Guinea & Guinea-Bissau & Guyana \\
\hline Haiti & Honduras & Hungary & India & Indonesia & Iran & Iraq \\
\hline Jamaica & Jordan & Kazakhstan & Kenya & Kiribati & Korea, North & Korea, South \\
\hline Kosovo & Kyrgyzstan & Laos & Latvia & Lebanon & Lesotho & Liberia \\
\hline Libya & Liechtenstein & Lithuania & Luxembourg & Macau & Macedonia & Madagascar \\
\hline Malawi & Malaysia & Maldives & Mali & Malta & Marshall Islands & Mauritania \\
\hline Mauritius & Mexico & Micronesia & Moldova & Monaco & Mongolia & Montenegro \\
\hline Morocco & Mozambique & Namibia & Nauru & Nepal & $\begin{array}{l}\text { Netherlands } \\
\text { Antilles }\end{array}$ & Nicaragua \\
\hline Niger & Nigeria & North Korea & Oman & Pakistan & Palau & $\begin{array}{l}\text { Palestinian } \\
\text { Territories }\end{array}$ \\
\hline Panama & $\begin{array}{l}\text { Papua New } \\
\text { Guinea }\end{array}$ & Paraguay & Peru & Philippines & Poland & Portugal \\
\hline Romania & Russia & Rwanda & $\begin{array}{l}\text { Saint Kitts and } \\
\text { Nevis }\end{array}$ & Saint Lucia & $\begin{array}{l}\text { Saint Vincent } \\
\text { and the } \\
\text { Grenadines }\end{array}$ & Samoa \\
\hline San Marino & $\begin{array}{l}\text { Sao Tome and } \\
\text { Principe }\end{array}$ & Senegal & Serbia & Seychelles & Sierra Leone & Sint Maarten \\
\hline Slovakia & Slovenia & Solomon Islands & Somalia & South Africa & South Korea & South Sudan \\
\hline Sri Lanka & Sudan & Suriname & Swaziland & Syria & Taiwan & Tajikistan \\
\hline Tanzania & Thailand & Timor-Leste & Togo & Tonga & Tunisia & Turkey \\
\hline Turkmenistan & Tuvalu & Uganda & Ukraine & Uruguay & Uzbekistan & Vanuatu \\
\hline Vietnam & Yemen & Zambia & Zimbabwe & & & \\
\hline
\end{tabular}


Appendix Table A2 Examples of new and old products

\begin{tabular}{ll}
\hline \hline HS 6-digit & Product name \\
\hline Panel A: New product examples \\
\hline 540231 & Textured yarn nes, nylon, polyamide $<$ 50dtex not retai \\
670210 & Artificial flowers foliage fruit, articles, plastic \\
701710 & Fused quartz laboratory, hygienic or pharmeutical war \\
842831 & Mine conveyors/elevators, continuous action \\
900820 & Microfilm, microfiche or other microform readers \\
\hline Panel B: Old product examples \\
\hline 070110 & Potatoes seed, fresh or chilled \\
250510 & Silica sands and quartz sands \\
400211 & Styrene-butadiene rubber (SBR/XSBR) latex \\
611610 & Gloves impregnated or coated with plastic, rubber, knit \\
700510 & Float glass etc sheets, absorbent or reflecting layer \\
\hline \hline
\end{tabular}

